\title{
Understanding otolith biomineralization processes: new insights into microscale spatial distribution of organic and mineral fractions from Raman microspectrometry
}

\author{
Aurélie Jolivet ${ }^{1,}{ }^{*}$, Jean-François Bardeau ${ }^{2}$, Ronan Fablet ${ }^{1,3}$, Yves-Marie Paulet $^{4}$, Hélène de Pontual ${ }^{1}$ \\ ${ }^{1}$ Ifremer, Laboratoire de Sclérochronologie des Animaux Aquatique STH/LASAA, Z.I. Pointe du diable, BP 70, \\ 29280 Plouzané, France \\ ${ }^{2}$ Laboratoire de Physique de l'Etat Condensé, Faculté des Sciences, Université du Maine, Avenue Olivier \\ Messiaen, 72085 Le Mans Cedex 09, France \\ ${ }^{3}$ Institut Telecom/ Telecom Bretagne, LabSTICC, Technopole Brest Iroise, CS83818, 29238 Brest Cedex 03, \\ France \\ ${ }^{4}$ LEMAR, UMR 6539 CNRS, Institut Universitaire Européen de la Mer, Place Nicolas Copernic, 29280 Plouzané, \\ France
}

*: Corresponding author : A. Jolivet, email address : Aurelie.Jolivet@ifremer.fr

\begin{abstract}
:
It is generally accepted that the formation of otolith microstructures (L- and D-zones) and in particular the organic and mineral fractions vary on a daily basis. Raman microspectrometry provides a nondestructive technique that can be used to provide structural information on organic and mineral compounds. We applied it to thin otolith sections of hake in order to address the following issues: (1) the simultaneous characterization of variations in the organic and mineral fractions both in the core area and along successive otolith microstructures; (2) elucidation of significant differences between these fractions; (3) quantification of the effects of etching and staining protocols on otolith structures. The primordium appeared as a punctual area depicting higher luminescence and greater concentrations in organic compounds containing $\mathrm{CH}$ groups. Sulcus side showed similar composition suggesting that the contact of the otolith with the macula and its orientation in otosac occur rapidly (about 10 days). The characterization of L- and D-zones in the opaque zones indicated that both structures contained organic and aragonitic fractions with cyclic and synchronous variations. Contrary to the results obtained after EDTA etching, L-zones depicted greater concentrations in organic compounds containing $\mathrm{CH}$ groups, whereas D-zones appear richer in aragonite. This organic fraction seemed to be revealed by Mutvei's staining and was affected by EDTA etching which suggests that it corresponds to the soluble fraction of organic matrix. Such results indicate that L- and D-zones differ in their respective organic constituents. Raman microspectrometry thus appears as a powerful technique to acquire quantitative information that is required for a better understanding of otolith biomineralization.
\end{abstract}

Keywords: Core - L- and D-zones - Aragonite - Staining - Acid etching 


\section{Introduction}

Otoliths are calcareous concretions in fish inner ears. Their accretional growth follows a circadian rhythm that is physiologically controlled and influenced by environmental conditions [1, 2]. The formation of daily L- and D-zones result, also referred to as microstructures as well as of opaque and translucent macrostructures (Figure 1). The otoliths act as biological archives providing the basis for the reconstruction of individual life traits and environmental parameters. They thus deliver invaluable information in fisheries sciences and marine ecology [3]. However in many cases the interpretation schemes of both structural and chemical information remain incomplete and debatable. New advances in the analysis and the understanding of otolith biomineralization, especially regarding the relationships between the physico-chemical characteristics of the accretion and the associated environmental and physiological conditions, are of key importance to fully exploit the potential of these biological archives [3, 4].

Overall the calcium carbonate fraction, mainly in aragonite form, represents 90-99 \% of the total mass of fish otoliths. The remaining 1-10\% includes the organic matrix, composed of collagens, proteoglycans and proteins [5-7]. The role of organic matrix in the formation of the deposited layer is not fully understood, although different studies have demonstrated that it controls the biomineralization of the otolith [7, 8]. L- and D-zones have been described as depicting different compositions in term of organic and mineral fractions [9-11] by global quantitative and fine scale qualitative experiments. To our knowledge, these compositions have never been quantified at a micro-scale. Given the spatial resolution and the capacity of simultaneously characterizing organic and mineral compounds, Raman micro-spectrometry is particularly well-suited to address these issues.

Raman micro-spectrometry is a non destructive technique which provides a quantitative characterization of vibrational physico-chemico features of both organic and 


\section{1}

mineral compounds. Regarding calcified structures, Raman micro-spectrometry permits discriminating vaterite, aragonite and calcite in otoliths of different species [12-15], and is also particularly well-suited to study the organic matrix of corals [16], the degradation of skeletal organic matrix [17] and mollusc shell pigments [18]. More recently Raman microspectrometry was used to identify and analyze variations of the characteristics of the organic matrix in fish otoliths [19].

Here, we use Raman micro-spectrometry to investigate physico-chemical variations in the organic and mineral constituents of fish otoliths in relation to observed micro-structures. Experiments are reported for thin sections of European hake (Merluccius merluccius) otoliths. Our main contributions are three-fold: 1) characterizing mineral and organic fractions within otoliths microstructures (namely, primordium and L- and D-zones); 2) elucidating significant differences between L- and D- zones; 3) highlighting the differential effects of etching and staining on the organic and mineral fractions of these zones.

[Figure 1 about here]

\section{Material and Methods}

\section{Otolith samples}

We considered a series of otoliths extracted from hake caught in the Bay of Biscay in June 2005 and 2007 or reared in controlled facilities (Table 1). Larval, juvenile and adult fish were available and fish size (total length) ranged from $4.3 \mathrm{~mm}$ (larva size) to $50 \mathrm{~cm}$. To obtain thin sections, the standard otolith preparation method consisted of: 1) embedding in epoxy resin, 2) sectioning in transverse or sagittal plane, 3) grinding, and 4) polishing to the core. Larval otolith was extracted under polarized light, mounted on an epoxy resin drop and directly analysed on sagittal plan without any further preparation. 
[Table 1 about here]

Etching and staining protocols

Etching was performed using a 5\% EDTA (ethylene diamine tetra-acetate) solution at pH 7. EDTA is as calcium chelator frequently used for otolith decalcification. Section S7 was exposed to the EDTA solution for a period of 90 seconds after which the sample was rinsed with milliQ water.

To enhance the optical contrast of otolith structures, otolith sections were stained. For this purpose, we used Mutvei's solution [20] composed in the following manner: $500 \mathrm{ml}$ 1\% acetic acid for $500 \mathrm{ml}$ 25\% glutaraldehyde and ca. 5 to $10 \mathrm{~g}$ alcian blue. The latter stains mucopolyssacharides and glycosaminoglycans. This dye also performs a slight etching of the surface as it contains diluted acetic acid. Section S8 was immersed in the Mutvei’s solution for $10 \mathrm{~min}$ at $45^{\circ} \mathrm{C}$ and subsequently rinsed with milliQ water.

\section{Analyses of fine-scale otolith structures}

Three different types of analysis were carried out at core area, micro-increments in L- and Dzones on 1) standard preparations, 2) EDTA etched preparations, and 3) preparations stained with Mutvei’s solution. Details about the analysis are summarized in Table 1.

For the core area, three transversal sections (S1-S3) were analysed. In addition, the sagittal section of an 18 days larva otolith (S4) was considered. Dorso-ventral Raman transects spectra centred on the primordium were acquired with steps varying from 2.5 to 6 $\mu \mathrm{m}$. For S4, the transect was $14 \mu \mathrm{m}$ long with points at 7, 12 and $14 \mu \mathrm{m}$. In addition, a 2D mapping centred on the primordium was acquired on S3. 

covering several successive increments were acquired in opaque zones of two sagittal otolith sections (S5 and S6). The sagittal plane was preferred to the transverse one as wider D- and L-zones, typically 2 and $4 \mu \mathrm{m}$ respectively, were observed. Regarding EDTA etching, Raman spectra were acquired before and after etching on

122 the opaque zone of S7 along a transect covering two D-zones and two L-zones. Raman measurements were carried out after staining within an opaque zone of S8 along a transect covering three D-zones and two L-zones.

\section{Raman spectrometry}

127 A micro-Raman spectrometer (Jobin-Yvon T64000) equipped with a confocal system and a 128 motorized microscope stage (for Raman mapping purpose) was used and specific experimental conditions were defined. A coherent spectrum argon/krypton ion laser was used to produce radiation with a wavelength of $514.5 \mathrm{~nm}$ and a good signal-noise ratio. The laser was focused onto the sample by using a microscope equipped with a x100 objective. The

132 resulting spatial resolution is about 1-2 $\mu \mathrm{m}$. The scattered light was analysed by a

133 spectrometer with a single monochromator (600 gratings $\mathrm{mm}^{-1}$ ), coupled to a nitrogen cooled 134 CCD detector. To check that the experimental setting is non-destructive for fish otoliths, several Raman spectra were recorded at the same points between 20 to $200 \mathrm{~mW}$. No heating

136 alteration was observed on spectra when controlling relative intensities and profiles. For the 137 analysis of the otolith core and microstructures, a $50 \mathrm{~mW}$ laser power was selected. Stained 138 otoliths were analysed with a $10 \mathrm{~mW}$ laser. Spectra were accumulated two to four times with 139 exposure times varying from 30 to 300 s depending on the sample. The depth of analysis was 140 systematically set to $2 \mu \mathrm{m}$ below the surface to avoid possible contamination linked to surface 141 preparations. 


\section{Analysis of Raman spectra}

144 Raman spectra were corrected for background luminescence using baseline subtraction. In the 145 subsequent analysis, reported Raman spectra are baseline corrected and normalized with 146 respect to a reference acquisition time of $50 \mathrm{~s}$ and a reference of $50 \mathrm{~mW}$ laser. The positions 147 and integrated intensities of identifiable vibrational bands on spectra were determined using 148 the LABSPEC software. Optical images under transmitted light were acquired before each 149 analysis to record the locations of Raman analysis for subsequent treatment.

\section{Quantitative analysis for characterization of aragonitic and organic fractions}

152 With respect to Raman spectra of fish otoliths, 14 vibrational bands can be directly attributed

153 to aragonite [21]: symmetric stretching mode $\left(1085 \mathrm{~cm}^{-1}\right)$, anti-symmetric stretching modes 154 (1462, $\left.1574 \mathrm{~cm}^{-1}\right)$, in plane bending modes of $\mathrm{CO}_{3}{ }^{2-}\left(701\right.$ and $\left.705 \mathrm{~cm}^{-1}\right)$ and the lattice modes (9 peaks between 113 and $284 \mathrm{~cm}^{-1}$ ) (Figure 2A). The broad bands observed at 2950-3070 and $3390 \mathrm{~cm}^{-1}$ are respectively associated to $\mathrm{CH}$ and $\mathrm{OH}$ stretching modes (Figure 2B). The aragonite peak at $1085 \mathrm{~cm}^{-1}$ was chosen as the reference peak for the spectra normalization. In this study, we considered the ratio between the response of the $\mathrm{CH}$-group and the peak of aragonite at $1085 \mathrm{~cm}^{-1}$ as a proxy of the ratio between the organic and mineral fraction of the otolith structures.

Figure 3 shows the Raman spectra of Mutvei's solution and of the stained otolith. The 
167 stained organic matrix vs the aragonitic fraction. As the aragonitic peak at $1085 \mathrm{~cm}^{-1}$ is

168 occluded by the Raman response of the dye, we used the peaks between 100 and $300 \mathrm{~cm}^{-1}$ as

169 the aragonitic references. The ratio between this aragonitic reference and the dye-specific

170 Raman response between 1200 and $1700 \mathrm{~cm}^{-1}$ was then calculated.

[Figure 3 about here]

\section{Glossary}

174 For the sake of clarity, we abbreviated organic matrix (OM), Aragonite (AR) represented by 175 the band at $1085 \mathrm{~cm}^{-1}$, CH-group (CH) the whole bands observed in the region $2950-3070 \mathrm{~cm}^{-}$

$176{ }^{1}$, OH-group $(\mathrm{OH})$ bands in the region 3390-4000 $\mathrm{cm}^{-1}$, and OM/AR, CH/AR and OH/AR, the 177 respective ratios between the integrated intensity of the bands described previously.

\section{Results}

\section{Core area}

181 For samples S1-S4, the main peaks of the Raman spectra acquired in the core area are reported in Table 2. Their wavelength and possible assignments to known vibrational modes are given and compared to previous results [19, 22-24].

[Table 2 about here] observed in conjunction with the primordium than the surrounding points. The intensities of amides and amino acids peaks reached maxima in the primordium (Figure 4B) as well as $\mathrm{CH}$

190 and OH groups (Figure 5A). Similar results were observed for S2-S4 samples as shown in 
192 The primordium was also shown to be 10 times more concentrated in $\mathrm{CH}$ than points located 193 at $18 \mu \mathrm{m}$ in the dorsal and ventral directions. Besides, the spatial distribution of the $\mathrm{CH} / \mathrm{AR}$ 194 ratio in the core area (30 $\mu \mathrm{m} \times 40 \mu \mathrm{m}$ mapping around the primordium) of S3 is reported

195 (Figure 6). Whereas the decrease of the CH/AR ratio along the anti-sulcus, dorsal and ventral 196 directions is isotropic and similar to the profile depicted in Figure 5, the sulcus area is 197 characterized by a greater $\mathrm{CH} / \mathrm{AR}$ ratio.

198

199

200

201

202

203

204

205

206

207

208

209

210

211

212

213

214

215

216

[Figure 4-6 about here]

\section{L- and D-zones}

Analyses of L- and D-zones were carried out on S5 and S6. The Raman spectra of one L-zone and one D-zone are shown in Figure 7 along with the evolution of the AR, CH (Figure 8B) and $\mathrm{CH} / \mathrm{AR}$ ratio (Figure $8 \mathrm{C}$ ) along the transects considered. $\mathrm{OH}$-response was relatively stable compared to the $\mathrm{CH}$-signature, which varies according to alternating L- and D-zones (Figure 7). Both $\mathrm{CH}$ and $\mathrm{AR}$ responses showed cyclic variations but different ranges of variations (Figure 8B). Cycles with maxima located on L-zones and minima on D-zones were also observed for $\mathrm{CH} / \mathrm{AR}$ (Figure 8C). L-zones display a greater relative concentration in $\mathrm{CH}$ and D-zones a greater relative concentration of AR (Figure 8B). Similar results were obtained from the analysis of the second S6 sample.

[Figure 7-8 about here]

\section{Effects of EDTA etching}

The variation of $\mathrm{CH} / \mathrm{AR}$ along the considered transects before and after etching is shown in Figure 9. Whereas $\mathrm{CH} / \mathrm{AR}$ depicted a maximum response in L-zones before etching, the 
maxima were located in D-zones after etching. AR responses after etching were lowered by a

218 factor of 0.8 . On the contrary, $\mathrm{CH}$ variations were greater by a factor of 1.3 after etching. This resulted in a greater $\mathrm{CH} / \mathrm{AR}$ after etching (Figure 9).

[Figure 9 about here]

\section{Effects of staining}

The analyses of the Raman responses of the AR fraction and of the dye after otolith staining with Mutvei's solution are reported in Figure 10 for a transverse otolith section. Optically Lzones displayed greater degree of staining. The Raman response of the Mutvei's dye on otolith showed cyclic variations in phase with the variations in AR. Maxima are located in Lzones (Figure 10A), and the ratio between these two signatures varied according to cyclic behaviour with maxima in L-zones (Figure 10B).

\section{Discussion}

\section{Core}

235 The analysis of the Raman spectra confirmed that primordium is a very specific point of the otolith with a greater concentration of $\mathrm{CH}$ and other organic compounds, such as collagen and amino acids, compared to other areas of the otolith. SEM observations lead to similar

238 conclusions with the primordium being detected as a point of greater density [25]. According 239 to Pisam et al. [26] this structure is highly concentrated in glycogen and collagens. The 240 analysis of the Raman spectra also showed that this feature was very punctual, corresponding to the primordium (about $2 \mu$ m width). Zhang et al. [19] recently reported a qualitative Raman 
characterization of small yellow croaker and discussed the identification of main organic

243 compounds namely collagen with signatures of amides I, III, IV and V and aromatic amino

244 acid such as phenylalanine, tyrosine and tryptophan. It is worth noting that Zhang et al. [19]

245 did not show and discuss the 1050-1200 $\mathrm{cm}^{-1}$ spectral region. For this reason, no comparison

246 can be made in this frequency range. Otherwise, most of the peaks found in our study have

247 been observed by Zhang et al. [19] except Phe-signatures at 1003 and $1031 \mathrm{~cm}^{-1}$ and Trp-peak

248 at $1555 \mathrm{~cm}^{-1}$ that might be masked by the strong aragonite signatures at 1085 and $1574 \mathrm{~cm}^{-1}$

249 respectively. The peak observed at $1272 \mathrm{~cm}^{-1}$ in our spectra was integrated in a larger band

250 (1206 and $1280 \mathrm{~cm}^{-1}$ ) with maximum at $1234 \mathrm{~cm}^{-1}$. In contrary, some peaks observed for

251 samples S1-S3 that were mentioned by Zhang et al. [19]. These peaks correspond to Tyr-

252 signatures at 1185 and $1610 \mathrm{~cm}^{-1}$, CN group at $1110 \mathrm{~cm}^{-1}$ and $\mathrm{CH}$-stretch at $3067 \mathrm{~cm}^{-1}$.

253 The 2D mapping of the region surrounding the primordium exhibited interesting

254 features. The concentration of the $\mathrm{CH}$-related compounds was found to decrease from the

255 primordium zone along the dorsal, ventral and anti-sulcus directions. Regarding the sulcus

256 area, a similar initial decrease was observed up to $9 \mu \mathrm{m}$ from the primordium. Subsequently,

257 the concentration of the $\mathrm{CH}$-related compounds increased again, up to values comparable to

258 those of the primordium zone. It is known that the sulcus zone is in contact with the macula

259 [27-29]. Moreover, the cells of the macula and of the adjacent zone are the sources of both

260 organic precursors and calcium ions in the endolymph [30]. Given the distance from the

261 primordium to the valley is about $9 \mu \mathrm{m}$, this observation suggests that the otolith was in close

262 proximity to the macula at a recent stage and thus oriented in the otosac. Such link would be

263 established at about 10 days post hatching [31].

264

\section{$\mathrm{L}$ and D-zones}


Previous studies on the characterization of L- and D-zones concluded that D-zones were

267 richer in OM than L-zones [25, 32]. Such characterizations of L- and D-zones were carried 268 out after EDTA etching. Under this condition, the reported Raman characterizations provided 269 similar results. Variations of AR responses depicted maxima located on L-zones, and 270 conversely for $\mathrm{CH}$, such that the relative proportion of $\mathrm{CH}$ vs $\mathrm{AR}$ was greater in the D-zones 271 than in L-zones after etching.

272 The analysis of the Raman spectra on L- and D-zones before EDTA etching led to 273 different conclusions. The responses of the organic compounds and aragonitic fraction as well 274 as the $\mathrm{CH} / \mathrm{AR}$ were greater on L-zones than on D-zones. As a consequence, these results contradict the widely accepted model stating that organic material concentration is greater in D-zones [1]. Whereas differences in crystal organization (e.g., crystal orientation and density) 277 might affect the absolute values of the responses of the aragonite and organic compounds, 278 such physical properties should not affect the CH/AR. L-zones are richer in CH-related 279 organic fraction (relatively to the AR fraction) which suggests that L- and D-zones are 280 associated with different biomineralization processes. Both of these processes involve the 281 biomineralization of organic and mineral factions but some organic compounds being more 282 specific to L-zones.

The comparison of the results before and after etching pointed out that the action of EDTA etching reversed the analysis of the $\mathrm{CH} / \mathrm{AR}$ in L- and D-zones. It is shown that EDTA 285 etching acted differently on L- and D-zones. Hence, L- and D-zones did not only differ in the 286 relative proportions of organic and mineral compounds but also in their structural 287 organization, such that D-zones are less sensitive to EDTA etching. D-zones appeared to be 288 richer in $\mathrm{CH}$ after etching. That could be explained by highlighted $\mathrm{CH}$ signature after AR 289 etching. As suggested by SEM observations of thin otolith sections [25, 32] D-zones may be 290 associated with a denser organic mesh, which $\mathrm{CH}$ organic compounds would weakly 
participate to, such that the overall deposited structure would be more stable in D-zones. This

292 inversion presupposed that L- and D-zones contained different OM compositions with Lzones richer in compounds that are soluble in EDTA.

Mutvei’s staining reveals etch-resistant lines called growth lines and etched depressions called growth increments [20]. Alcian blue in Mutvei’s solution is used as an indicator of acid mucopolyssacharides [33] and underlined carbon and nitrogen content of carbohydrates [34]. These compounds have been detected in the soluble organic matrix extracted from several fish species (Salmo salar [35]; Oncorhynchus mykiss and Psetta maxima [36] and Gadus morhua [37]). L-zones were optically blue-stained by the dye and the agent signature followed that of AR. These results corroborated the above conclusion stating that L-zones are richer in organic compounds revealed by the dye, such as polysaccharides 302 (carbohydrates such as glycogen). Mutvei's staining was also shown to react more strongly 303 with organic compounds soluble in EDTA [20]. Therefore, the agreement between Raman characterization of $\mathrm{CH}$ responses and Mutvei's staining in L-zones may suggest that $\mathrm{CH}$ responses are partly associated with the EDTA-soluble fraction of the OM. In Murayama et al. [6], the OMP-1, a collagen-like protein assumed to be involved in structuring the otolith biomineralization, was shown to be weakly present in the EDTA-soluble organic fractions. Such a structuring organic fraction would be relatively more present in the D-zones such that 309 these zones would be less affected by EDTA etching, providing an explanation to the 310 inversion observed before and after acid etching in terms of relative proportion of the organic 311 and mineral compounds.

312 The agreement between the Raman characterization of the responses of $\mathrm{CH}$ and 313 Mutvei's staining in L- and D-zones may also be interpreted as an evidence that $\mathrm{CH}$ 314 signatures are associated with otolith organic compounds such as polysaccharides, 315 glycosaminoglycans and proteoglycans. An additional evidence supports this assumption. 
Mutvei’s solution was shown to underline water-soluble macromolecules (polysaccharides)

317 previously reported to play a key role in biomineralization and in particular in the nucleation

318 of otolith [26]. This is in accordance with the strong CH-response observed on Raman spectra 319 on the primordium.

\section{Conclusion}

322 A lot of effort have been devoted to the analysis of the chemical composition of the otolith

323 [38] at scales from one up to hundreds of micrometers depending on the chemical signatures of interest (e.g., elemental composition, isotopic ratios) and on the considered analytical method (e.g., WDS, LA-ICPMS, IRMS) [38-40]. Such chemical analysis provide data that are required for specific fisheries issues (e.g. reconstructing individual life traits, analysing

327 population structure etc. ). However they do not supply information on the relative organic 328 and mineral fractions of the otolith which knowledge plays a key role in the understanding of the underlying biomineralization processes.

Because Raman micro-spectrometry (unlike Fourier transformed infrared spectroscopy) has potential for non destructive and micro-scale diagnostics, this study was designed to quantify and characterize organic and mineral fractions in otoliths structures. The main contributions, exemplified here by the determination of the relative spatial variations of the $\mathrm{AR}$ and $\mathrm{CH}$ fractions are three-fold: 1) the simultaneous analysis of the organic and mineral fractions of the otolith; 2) a subscale analysis $(1 \mu \mathrm{m})$ corresponding to daily if not subdaily timescales on otolith sections;

3) a quantitative characterization through the

337 magnitude of specific peaks observed in the Raman spectra. The Raman-based analysis shows 338 that fine scale otolith structures depict variations both in absolute and relative concentrations 339 of mineral and organic compounds. This finding challenges the current perception of L- and 340 D- zones in terms of mineral and organic compounds. In relation to the daily eurhythmics 
observed in L- and D-zone deposition, concentrations in endolymph organic precursors and total $\mathrm{CO}_{2}$ depict circadian cycles [41-43], in antiphasic ryhtm [4, 44]. Raman spectra reflected cyclic variations according to alternation of L- and D-zones but with synchronous variations

344 between $\mathrm{CH}$ and AR. This could be explained by the fact that the $\mathrm{CH}$-signature does not 345 involve all the organic compounds present in the endolymph (proteins, collagens, 346 proteoglycans, inhibitor factor). In situ Raman analysis of the endolymph along a daily cycle 347 might validate this assumption.

Future work will be aimed at refining our analysis of the Raman spectra. In the present

349 study, we mainly focused on two specific Raman signatures, the responses of the aragonitic 350 fractions observed at $1085 \mathrm{~cm}^{-1}$ and the responses of organic compounds involving $\mathrm{CH}$ 351 groups observed at $2950 \mathrm{~cm}^{-1}$. Raman spectra convey much more information and future 352 works will aim to better relate Raman signatures to known specific organic compounds (e.g., 353 isolated proteins, sugars, proteoglycans) using complementary tools (electrophoresis or 354 immuno-histochemical analysis).

\section{$356 \quad$ References}

357 1. Panfili J, de Pontual H, Troadec H, Wright PJ (2002) Manual of fish 358 Sclerochronology. Ifremer-IRD Coeditions, Brest, France.

359 2. Pannela G (1971) Science 173: 1124-1127.

360 3. Campana SE (2005) Mar Freshwat Res 56: 485-495.

361 4. Allemand D, Mayer-Gostan N, de Pontual H, Boeuf G, Payan P (2007) Fish otolith 362 calcification in relation to endolymph chemistry. In: Baeuerlein E (ed.) Handbook of 363 Biomineralization: Biological aspects and structure formation.

364 5. Borelli G, Mayer-Gostan N, Merle PL, De Pontual H, Boeuf G, Allemand D, Payan P 365 (2003) Calcif Tissue Int 72: 717-725. 
6. Murayama E, Okuno A, Ohira T, Takagi Y, Nagasawa H (2000) Comp Biochem Physiol 126B: 511-520.

7. Murayama E, Takagi Y, Ohira T, Davis JG, Greene MI, Nagasawa H (2002) Eur J Biochem 269: 688-696.

8. Söllner C, Burghammer M, Busch-Nentwich E, Berger J, Schwarz H, Riekel C, Nicolson T (2003) Science 302: 282-286.

9. $\quad$ Campana SE (1999) Mar Ecol Progr Ser 188: 263-297.

10. McCreadie BR, Morris MD, Chen T-C, Rao DS, Finney WF, Widjaja E, Goldstein SA (2006) Bone 39: 1190-1195.

11. Payan P, De Pontual H, Edeyer A, Borelli G, Boeuf G, Mayer-Gostan N (2004) Can J Fish Aquat Sci 61: 1247-1255.

12. Gauldie RW, Sharma SK, Volk E (1997) Comp Biochem Physiol 118A: 753-757.

13. Melancon S, Fryer BJ, Ludsin SA, Gagnon JE, Yang ZP (2005) Can J Fish Aquat Sci 62: 2609-2619.

14. Tomás J, Geffen AJ (2003) J Fish Biol 63: 1383-1401.

15. Tzeng WN, Chang CW, Wang CH, Shiao JC, Iizuka Y, Yang YJ, You CF, Ložys L (2007) Mar Ecol Progr Ser 348: 285-295.

16. Kaczorowska B, Hacura A, Kupka T, Wrzalik R, Talik E, Pasterny G, Matuszewska A (2003) Anal Bioanal Chem 377: 1032-1037.

17. Perrin C, Smith DC (2007) C R Palevol 6: 253-260.

18. Hedegaard C, Bardeau J-F, Chateigner D (2006) J Mollus Stud 72: 157-162.

19. Zhang F, Cai W, Sun Z, Zhang J (2008) Anal Bioanal Chem 390: 777-782.

20. Schöne BR, Dunca E, Fiebig J, Pfeiffer M (2005) Palaeogeogr, Palaeoclimatol, Palaeoecol 228: 149-166.

390 21. Urmos J, Sharma SK, Mackenzie FT (1991) Am Miner 76: 641-646. 
22. Careche M, Herrero AM, Rodriguez-Casado A, Del Mazo ML, Carmona P (1999) J Agr Food Chem 47: 952-959.

23. Ikoma T, Kobayashi H, Tanaka J, Walsh D, Mann S (2003) Int J Biol Macromol 32: 199-204.

24. Piot O, Autran J-C, Manfait M (2000) J Cereal Sci 32: 57-71.

25. Morales-Nin B (1987) Ultrastructure of the organic and inorganic constituents of the otoliths of the sea bass. In: Summerfeld RC, Hall GE (eds) The Age and Growth of Fish. The Iowa State University Press, Ames, Iowa.

26. Pisam M, Jammet C, Laurent D (2002) Cell Tissue Res 310: 163-168.

27. Dunkelberger DG, Dean JM, Watabe N (1980) J Morphol 163: 367-377.

28. Fay RR (1984) Science 225: 951-954.

29. Platt C, Popper AN (1981) Fine structure and function of the ear. In: Tavolga WN, Popper AN, Fay RR (eds) Hearing and Communication in Fishes. Springer-Verlag, New York.

30. Pisam M, Payan P, LeMoal C, Edeyer A, Boeuf G, Mayer-Gostan N (1998) Cell Tissue Res 294: 261-270.

31. Alvarez P, Cotano U (2005) Fish Res 76: 379-391.

32. Secor DH, Dean JM, Laban EH (1992) Otolith removal and preparation for microstructural examination. In: Stevenson DK, Campana DK (eds) Otolith microstructure examination and analysis. Can Spec Publ Fish Aquat Sci.

33. Marxen JC, Hammer M, Gehrke T, Becker W (1998) Biol Bull 194: 231-240.

34. Alldredge AL, Passow U, Logan BE (1993) Deep Sea Res I 40: 1131-1140.

35. Wright PJ (1991) J Fish Biol 38: 625-627.

36. Borelli G, Mayer-Gostan N, De Pontual H, Boeuf G, Payan P (2001) Calcif Tissue Int 69: 356-364. 
416 37. Dauphin Y, Dufour E (2003) Comp Biochem Physiol 134A: 551-561.

417 38. de Pontual H, Geffen AJ (2002) Otolith microchemistry. In: Panfili J, de Pontual H, 418 Troadec H, Wright PJ (eds) Manual of Fish Sclerochronology. Coedition Ifremer-IRD, $419 \quad$ Brest, France.

420 39. de Pontual H, Lagardère F, Amara R, Bohn M, Ogor A (2003) J Sea Res 50: 199-210.

421 40. Tomás J, Geffen AJ, Millner RS, Pineiro CG, Tserpes G (2006) Mar Biol 148: 13994221413.

423 41. Borelli G, Guibbolini ME, Mayer-Gostan N, Priouzeau F, de Pontual H, Allemand D, 424 Puverel S, Tambutte E, Payan P (2003) J Exp Biol 206: 2685-2692.

425 42. Edeyer A, de Pontual H, Payan P, Troadec H, Sévère A, Mayer-Gostan N (2000) Mar $426 \quad$ Ecol Progr Ser 192: 287-294.

427 43. Mugiya Y (1987) Fish Bull 85: 395-401.

428 44. Payan P, de Pontual H, Boeuf G, Mayer-Gostan N (2004) C R Palevol 3: 535-547.

429 45. Briget Mary M, Ramakrishnan V (2005) Spectrochimica Acta Part A 62: 164-170. 
431 Table 1: Details on otoliths samples investigated by Raman micro-spectrometry: fish origin

432 and size $(\mathrm{cm})$, thickness $(\mu \mathrm{m})$ and type of otolith section (transversal or sagittal), preparation

433 method, analyzed area and characteristics of the analysis (T: transect, M: Mapping, D:

434 Distance between two analysed points).

\begin{tabular}{|c|c|c|c|c|c|c|c|c|}
\hline Name & Origin & $\begin{array}{l}\text { Size } \\
(\mathrm{cm})\end{array}$ & $\begin{array}{c}\text { Thickness } \\
(\mu \mathrm{m})\end{array}$ & Section & $\begin{array}{l}\text { Preparation } \\
\text { method }\end{array}$ & Area & \multicolumn{2}{|c|}{ Analysis } \\
\hline S1 & Rearing & 25 & 150 & Transversal & \multirow{8}{*}{ Standard } & \multirow{6}{*}{ Core } & $\mathrm{T}: 20 \mu \mathrm{m}$ & $\mathrm{S}: 6 \mu \mathrm{m}$ \\
\hline S2 & Wild & 33 & 394 & Transversal & & & $\mathrm{T}: 40 \mu \mathrm{m}$ & $\mathrm{S}: 2.5 \mu \mathrm{m}$ \\
\hline \multirow{3}{*}{ S3 } & \multirow{3}{*}{ Wild } & \multirow{3}{*}{20} & \multirow{3}{*}{325} & Transversal & & & $\mathrm{T}: 40 \mu \mathrm{m}$ & $\mathrm{S}: 2.5 \mu \mathrm{m}$ \\
\hline & & & & \multirow[t]{2}{*}{ Transversal } & & & \multirow{2}{*}{$\begin{array}{c}\text { 2D-M: } \\
30 \mu \mathrm{m} \mathrm{x} \\
40 \mu \mathrm{m}\end{array}$} & $\begin{array}{c}\mathrm{S} X: \\
2.5 \mu \mathrm{m}\end{array}$ \\
\hline & & & & & & & & S Y: $3 \mu \mathrm{m}$ \\
\hline S4 & Rearing & $4.3 \mathrm{~mm}$ & & Sagittal & & & $\mathrm{T}: 15 \mu \mathrm{m}$ & $\begin{array}{c}7,12,14 \\
\mu \mathrm{m}\end{array}$ \\
\hline S5 & Wild & 21 & 100 & Sagittal & & \multirow{4}{*}{$\begin{array}{c}\text { L- and D- } \\
\text { zones }\end{array}$} & $\mathrm{T}: 44 \mu \mathrm{m}$ & S: $0.7 \mu \mathrm{m}$ \\
\hline S6 & Wild & 34 & 299 & Sagittal & & & $\mathrm{T}: 36 \mu \mathrm{m}$ & S: $0.8 \mu \mathrm{m}$ \\
\hline S7 & Wild & 20 & 375 & Transversal & Acid etching & & $\mathrm{T}: 12 \mu \mathrm{m}$ & $\mathrm{s}: 0.7 \mu \mathrm{m}$ \\
\hline S8 & Wild & 30 & 132 & Transversal & Mutvei's staining & & $\mathrm{T}: 5 \mu \mathrm{m}$ & $\mathrm{S}: 0.2 \mu \mathrm{m}$ \\
\hline
\end{tabular}

435 
436 Table 2: Wavenumbers and assignments of the Raman bands observed in the core area:

437 comparisons between results reported by Zhang et al. (2008) on small yellow croaker and

438 sample S1 from our study. In the table, NS is indicated a non significant intensity on Raman 439 spectra.

\begin{tabular}{|c|c|c|}
\hline $\begin{array}{c}\text { Wavenumbers }\left(\mathrm{cm}^{-1}\right) \\
\text { Zhang (2008) }\end{array}$ & $\begin{array}{c}\text { Wavenumbers }\left(\mathrm{cm}^{-1}\right) \\
\text { Samples S1-S4 }\end{array}$ & Band attribution [19, 22-24, 45] \\
\hline & 641 & $\left(\mathrm{SO}_{4}\right)^{2-}$ asym bend \\
\hline 765 & 755 & Trp, Amide IV, V \\
\hline 830 & 824 & $v$ - ring, Tyr, Ac Asp \\
\hline 853 & 853 & $\delta(\mathrm{CCH})$ ring, $v(\mathrm{C}-\mathrm{C}), \mathrm{Tyr}, \mathrm{Ac}$ asp \\
\hline 880 & 878 & $\delta(\mathrm{CCH})$ ring, Trp, Val, Hyp \\
\hline 940 & 937 & Nonaromatic v(C-C), Lys, Val, Leu \\
\hline 1003 & NS & Phe \\
\hline \multirow[t]{5}{*}{1031} & NS & Phe \\
\hline & 1085 & Aragonite \\
\hline & 1110 & $v \mathrm{CN}$ \\
\hline & 1185 & Tyr \\
\hline & $1200-1272$ & amide III \\
\hline 1272 & NS & amide III \\
\hline 1297 & 1297 & $\delta(\mathrm{C}=\mathrm{H})$, phospholipids \\
\hline 1443 & 1444 & $\mathrm{CH}_{2}, \mathrm{CH}, \mathrm{CH}_{3}$ bending \\
\hline 1461 & 1460 & Aragonite \\
\hline 1555 & NS & Trp \\
\hline \multirow[t]{2}{*}{1574} & 1574 & Aragonite \\
\hline & 1610 & Trp, Phe, Tyr v-ring \\
\hline 1660 & & Amide I \\
\hline 2852 & 2851 & $v\left(\mathrm{CH}_{2}\right)_{\text {sym }}$ lipids \\
\hline 2882 & 2876 & $v\left(\mathrm{CH}_{2}\right)_{\text {asym }}$ lipids, $v\left(\mathrm{CH}_{2}\right)_{\text {sym }}$ proteins \\
\hline \multirow[t]{2}{*}{2942} & 2941 & $\begin{array}{c}v\left(\mathrm{CH}_{3}\right)_{\text {sym }} \text { proteins and lipids, } v\left(\mathrm{CH}_{2}\right)_{\text {asym }} \\
\text { proteins }\end{array}$ \\
\hline & 3067 & CH stretch \\
\hline
\end{tabular}




\section{Figure legends}

442 Figure 1: Otolith structures at macro and microsocopic scales. a) Transverse section of a hake 443 otolith observed under reflected light showing opaque $(\mathrm{O})$ and translucent $(\mathrm{T})$ zones. Opaque 444 zones appear dark in transmitted light and bright in reflected light, and vice versa for 445 translucent zones. The core (C) corresponds to the area surrounding the primordium which is 446 the initial structure of otolith. Scale bar: $1 \mathrm{~mm}$. b) Thin transverse section of a hake otolith 447 under transmitted light microscopy. Primary increments composed of L- and D-zones are 448 clearly visible. Scale bar: $10 \mu \mathrm{m}$

449 Figure 2: Raman spectrum acquired on sample S5: the spectrum is dominated by the response of Aragonite (in dotted line) in the frequency range $100-4000 \mathrm{~cm}^{-1}$ but also reveals (B) the 451 presence of organic matrix (in black solid line) with main response on $\mathrm{CH}$-peak in the 452 frequency range $1000-4000 \mathrm{~cm}^{-1}$.

453 Figure 3: Raman spectra of Mutvei’s solution (in dark) and on S8 stained with Mutvei's 454 solution (in grey): the main signature of the staining agent between 500 and $2000 \mathrm{~cm}^{-1}(514.5$ $455 \mathrm{~nm}$ wavelength radiation, laser power of $20 \mathrm{~mW}$ and acquisition time of $20 \mathrm{~s}, 20$ times). The 456 two grey areas underline aragonite signatures $\left(100-300 \mathrm{~cm}^{-1}\right)$ and Mutvei's solution signatures $457 \quad\left(1200-1700 \mathrm{~cm}^{-1}\right)$ considered for the analyses.

458 Figure 4: (A) Typical view of S1 thin section obtained by light microscopy. The ventral (V) 459 and dorsal (D) area are shown as well as the source point positions (adjacent points are 460 separated by $6 \mu \mathrm{m}$ ) where spectra were collected (scale bar $=5 \mu \mathrm{m}$ ); (B) Raman spectra 461 acquired along the considered dorso-ventral transect in the $100-4000 \mathrm{~cm}^{-1}$ region. For clarity, 462 the spectra are only shifted (and not background corrected).

463 Figure 5: Normalized integrated intensity of OM/AR calculated for S1 to S4 in the 464 primordium area. (A) CH/AR (in dark) and $\mathrm{OH} / \mathrm{AR}$ (in grey) as a function of the distance 465 from the primordium for the sample S1. (B) Evolution of $\mathrm{CH} / \mathrm{AR}$ signature (CH/AR was 
normalised by $\mathrm{CH} / \mathrm{AR}$ from the primordium) as a function of the distance from the 467 primordium for samples S1 to S4.

468 Figure 6: (A) View of S3 thin section under light microscopy. The rectangle (30 $\mu \mathrm{m} \times 40$ $469 \mu \mathrm{m})$ centred on primordium, represents the 2D Raman mapping area: step increments were 470 fixed to $3 \mu \mathrm{m}$ and $2.5 \mu \mathrm{m}$ in the $\mathrm{X}$ and $\mathrm{Y}$ directions respectively (scale bar $=10 \mu \mathrm{m}$ ); (B) $\mathrm{XY}$ 471 micro Raman mapping of the normalized integrated intensity of CH/AR (D: dorsal, V: 472 ventral, S: sulcus AS: antisulcus). Coordinates were focused on primordium $(\mu \mathrm{m})$.

473 Figure 7: (A) Typical view of S5 thin section obtained by light microscopy; (B) Raman 474 spectra in the $2500-4000 \mathrm{~cm}^{-1}$ region of one L-zone (dark spectrum) and one D-zone (grey 475 spectrum) on S5 (scale bar $=5 \mu \mathrm{m})$.

476 Figure 8: (A) Typical view of S5 thin section under light microscopy. Markers delimit the 477 successive L- and D-zones (scale bar $=5 \mu \mathrm{m}$ ); (B) Integrated Raman intensities of AR (dark 478 line) and $\mathrm{CH}$ (grey line) along the line direction. (C) Evolution of $\mathrm{CH} / \mathrm{AR}$ with D-zones 479 depicted as grey areas.

480 Figure 9: (A) Typical view of S7 thin section of otolith obtained under light microscopy 481 before acid etching. Markers delimit the successive L- and D-zones (scale bar $=5 \mu \mathrm{m})$; $(\mathrm{B})$ 482 Evolution of CH/AR before (grey line) and after (dark line) acid etching with D-zones marked 483 by grey areas.

484 Figure 10: Integrated surfaces of Mutvei’s and AR signatures and Mutvei’s/AR from Raman 485 spectra after Mutvei’s staining on sample S8. Analyses were made on transect covering 3 L486 zones and 2 D-zones. (A) Evolution of the AR (dark line) and Mutvei’s solution (grey line) 487 responses on otolith. (B) Evolution of the ratio between Mutvei's and AR signatures as a 488 function of the position along the transect. 
489 Figure 1:

$490 \quad$ (A)

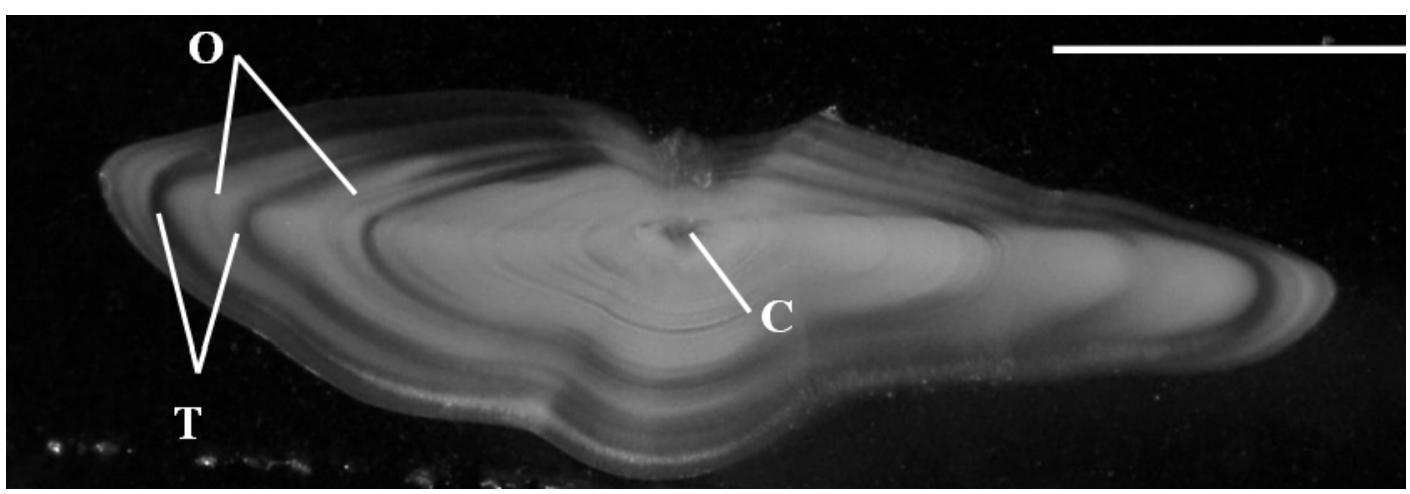

491

492 (B)

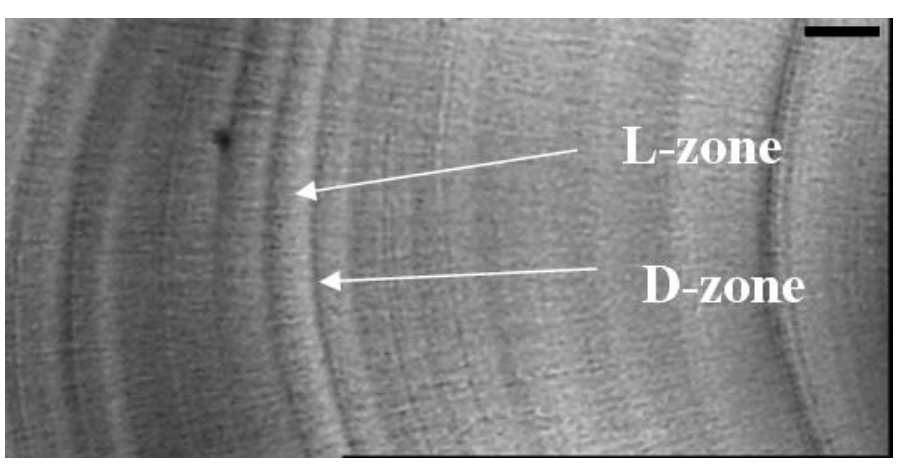

493 


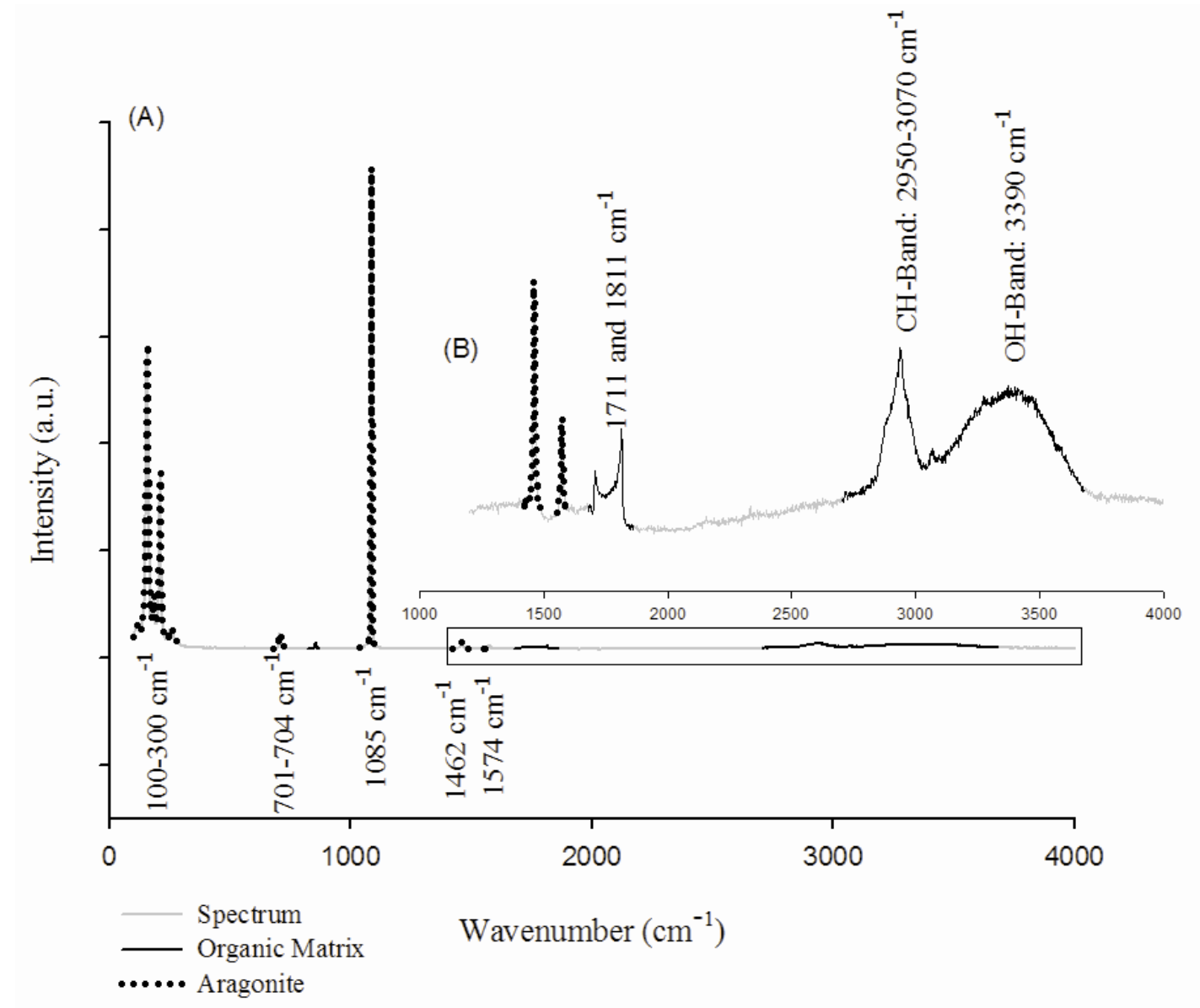

495 
496 Figure 3:

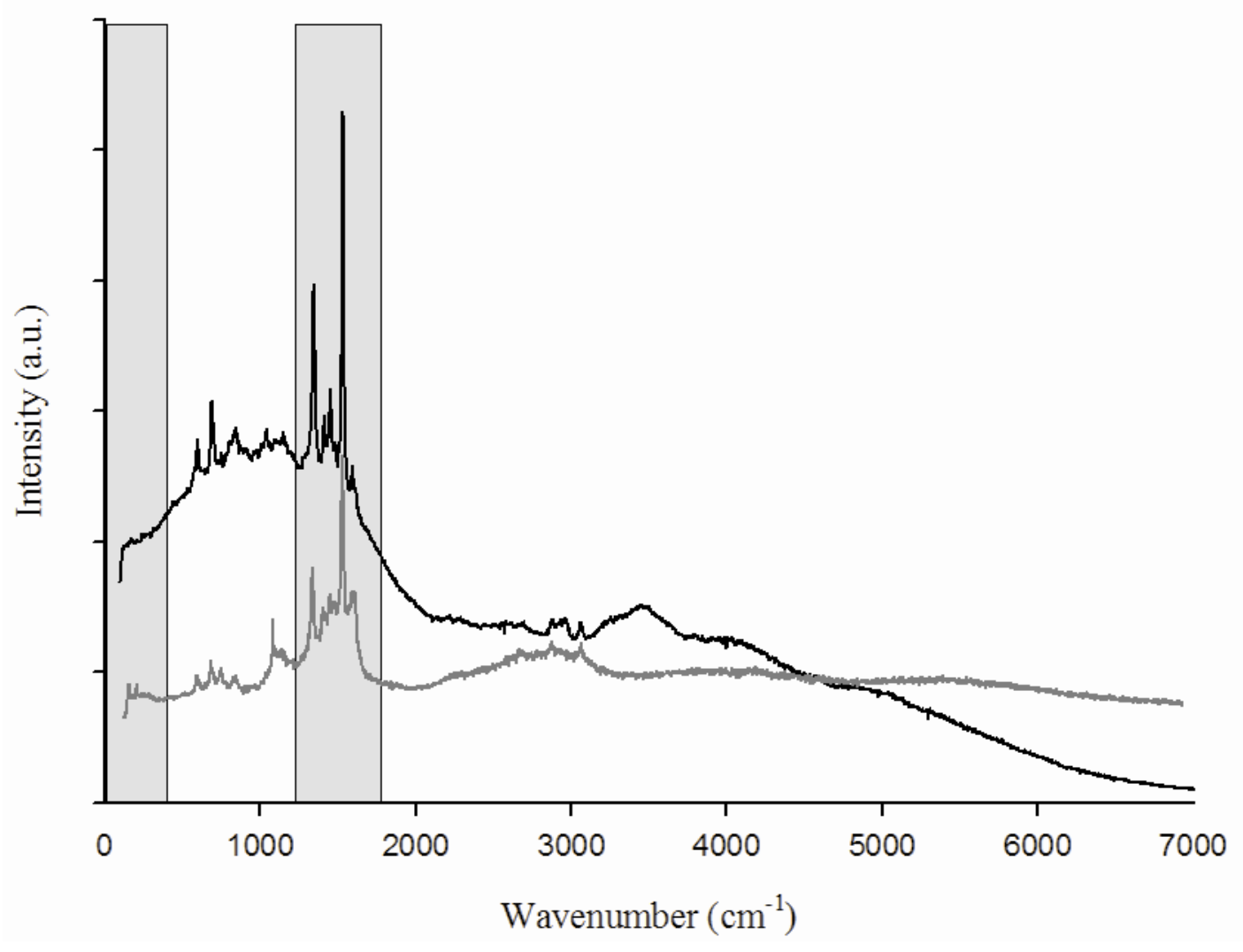

497 
$498 \quad$ Figure 4:

$499 \quad$ (A)

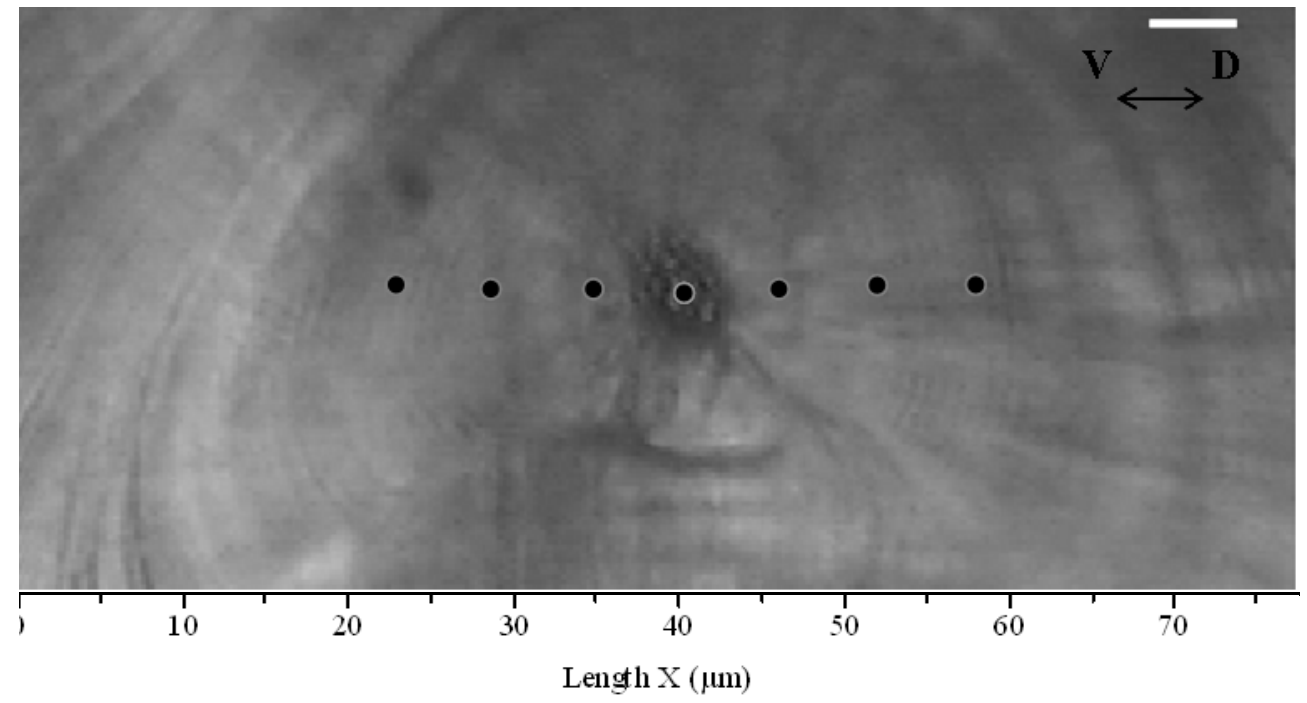

500

(B)

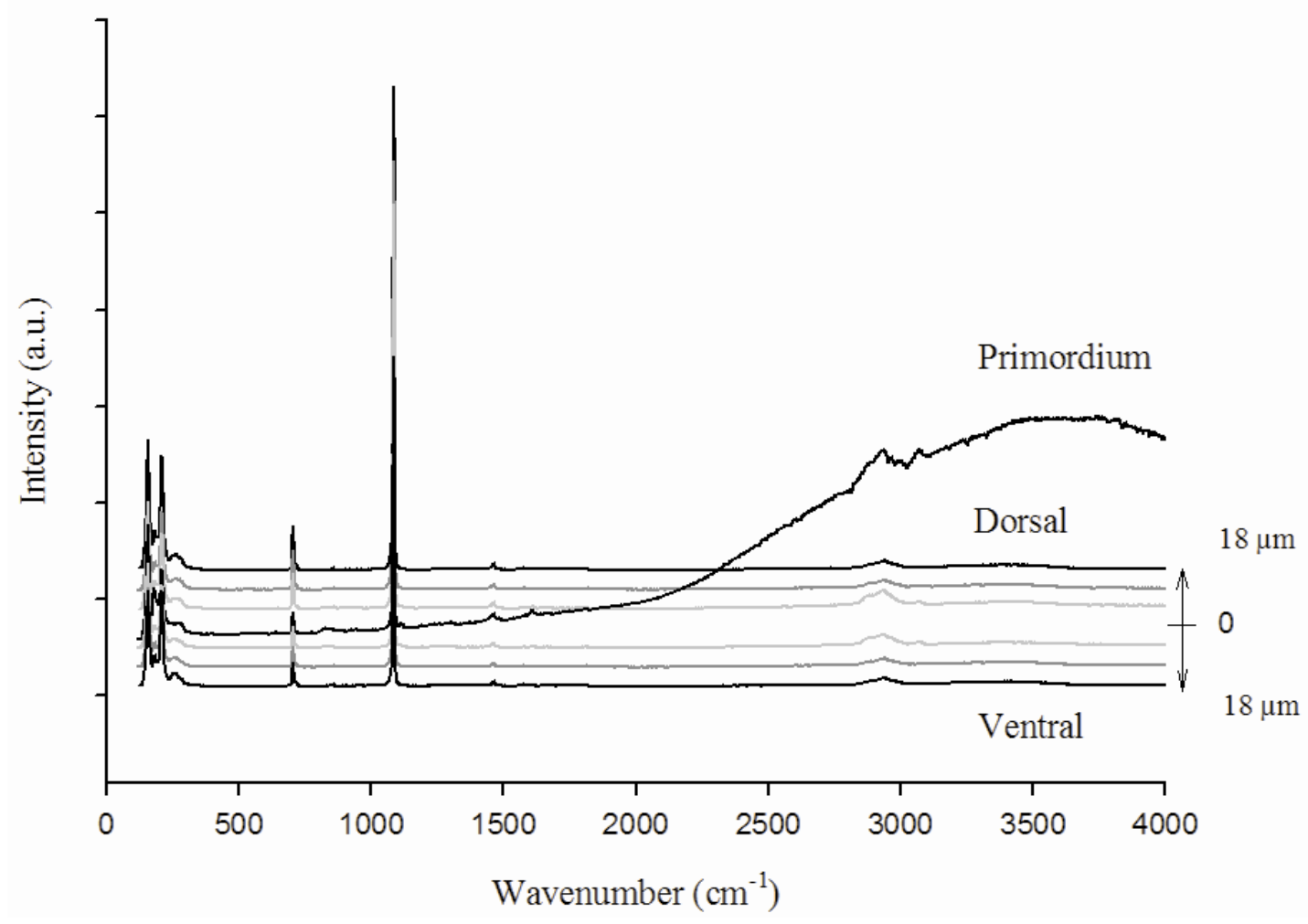


503

504

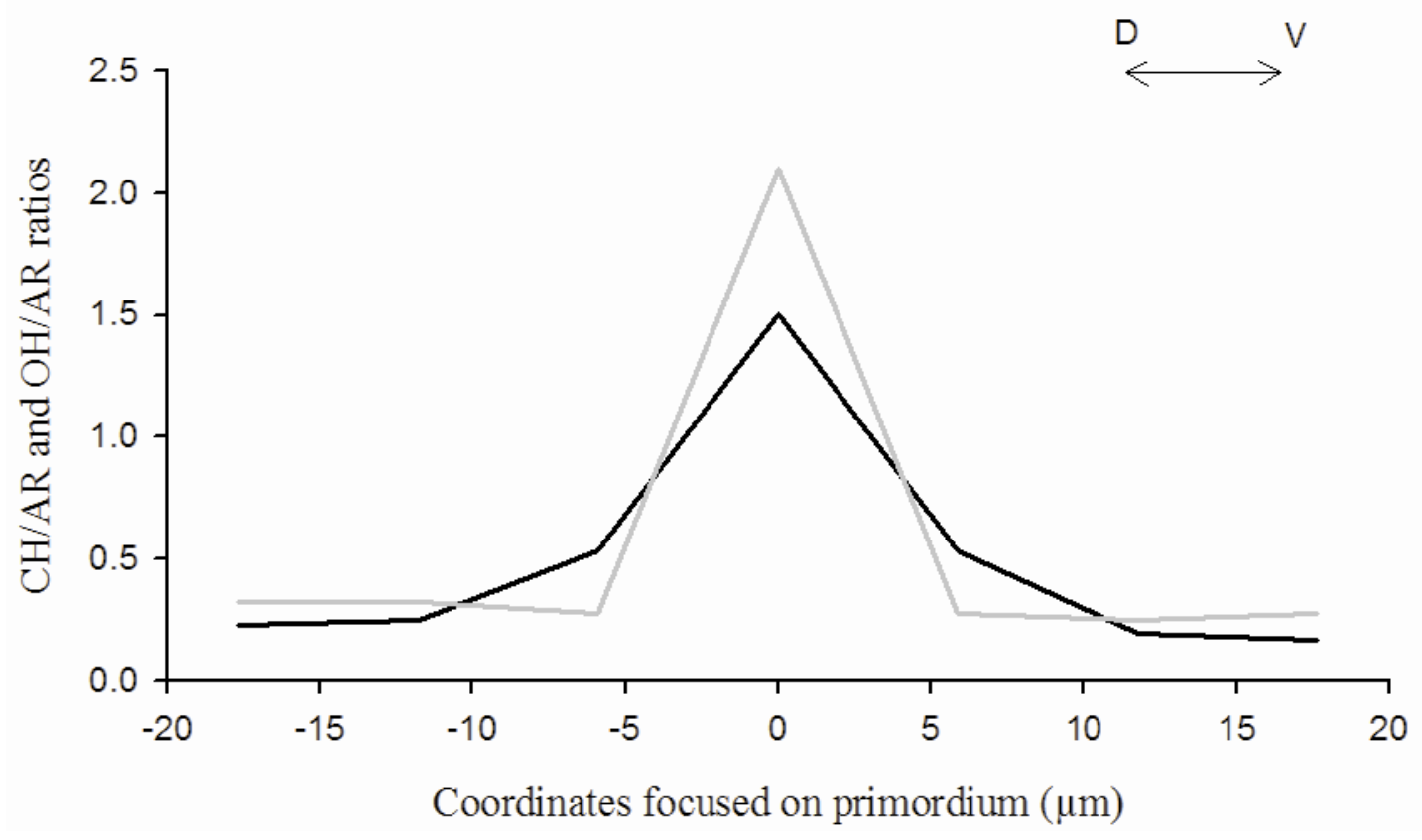

505 Figure 5:

(A)

506

(B)

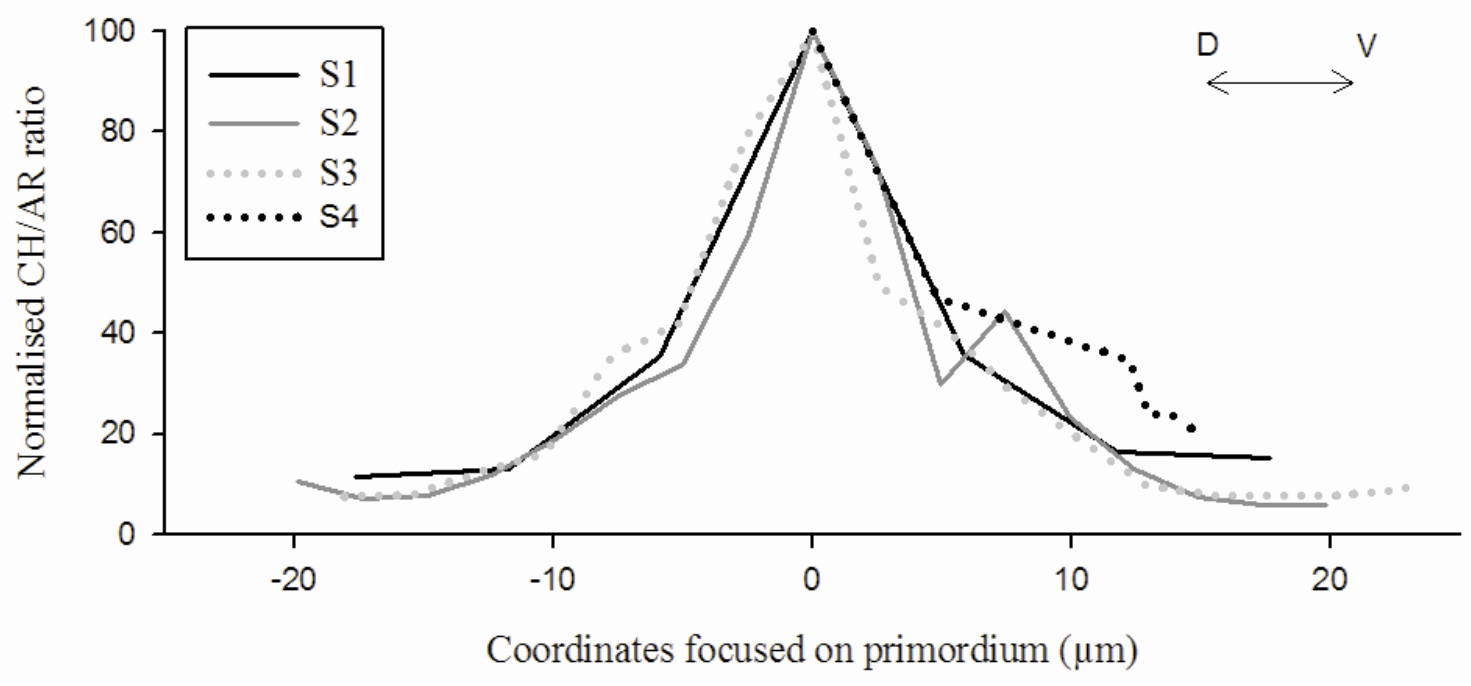


508 Figure 6:

$509 \quad$ (A)

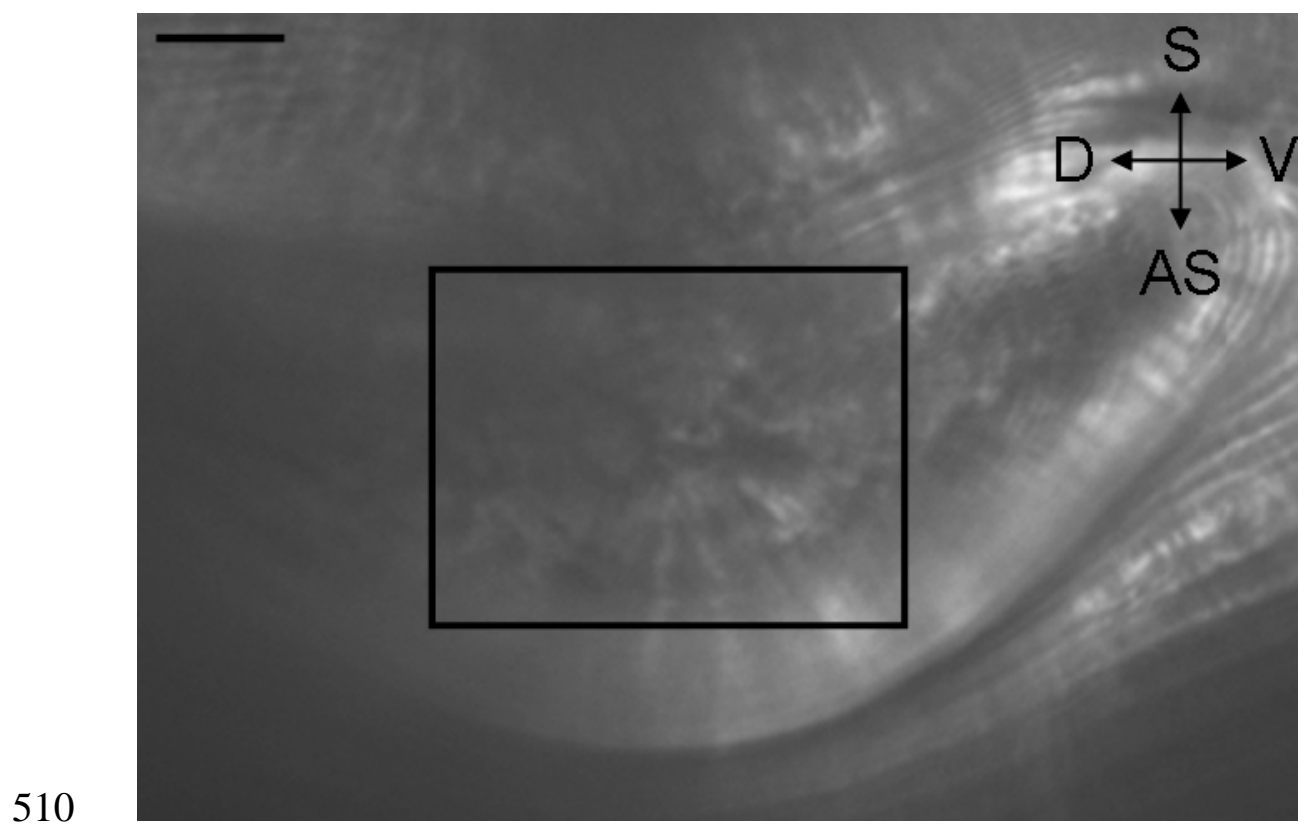

511 (B)

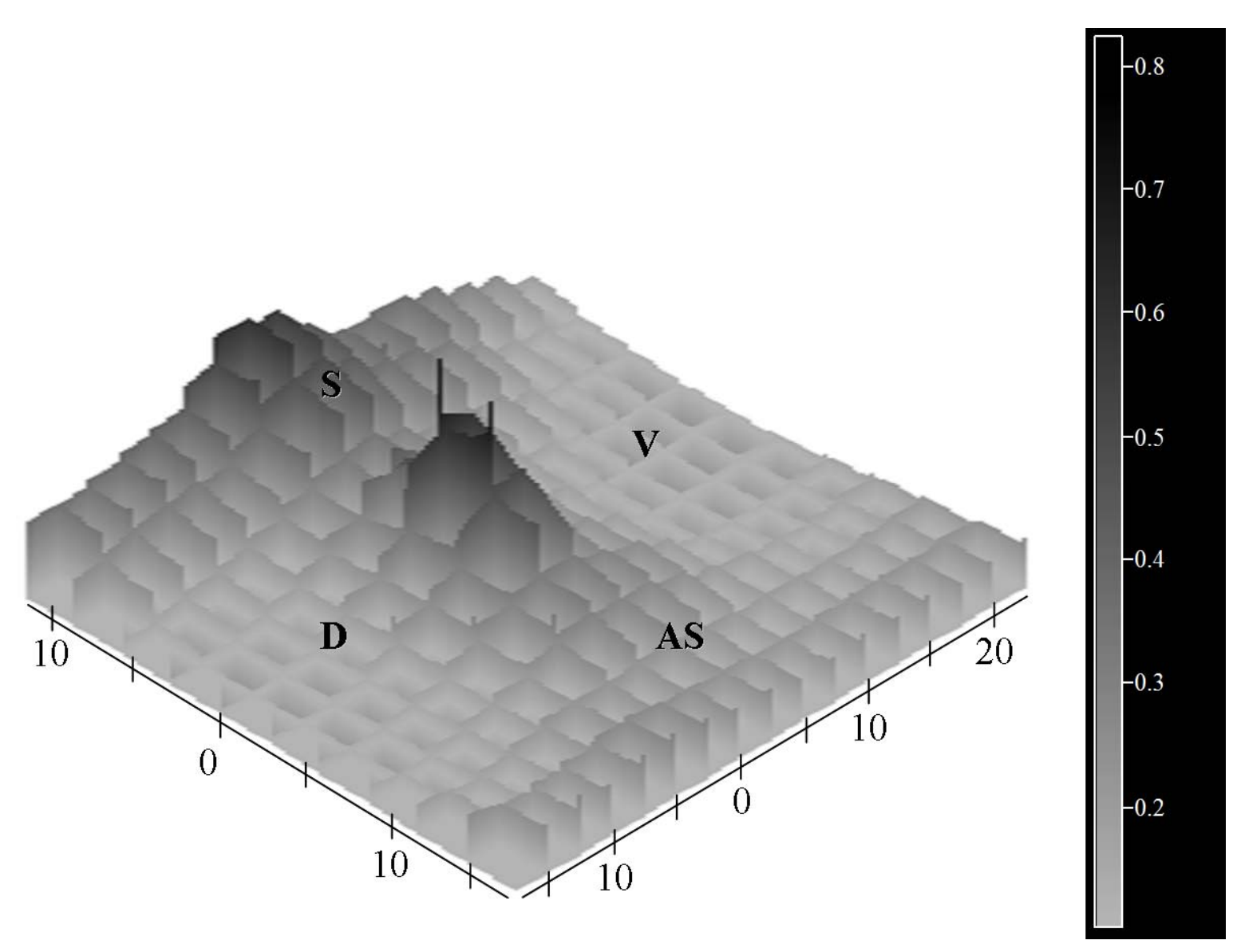


513 Figure 7:

514 (A)

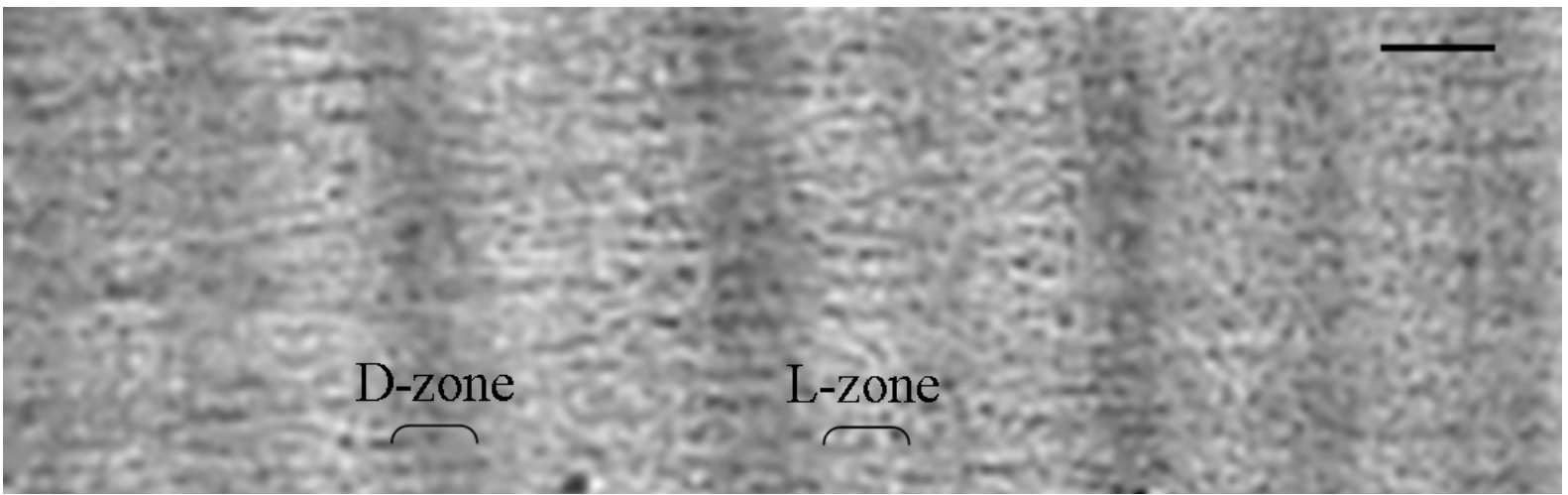

515

(B)

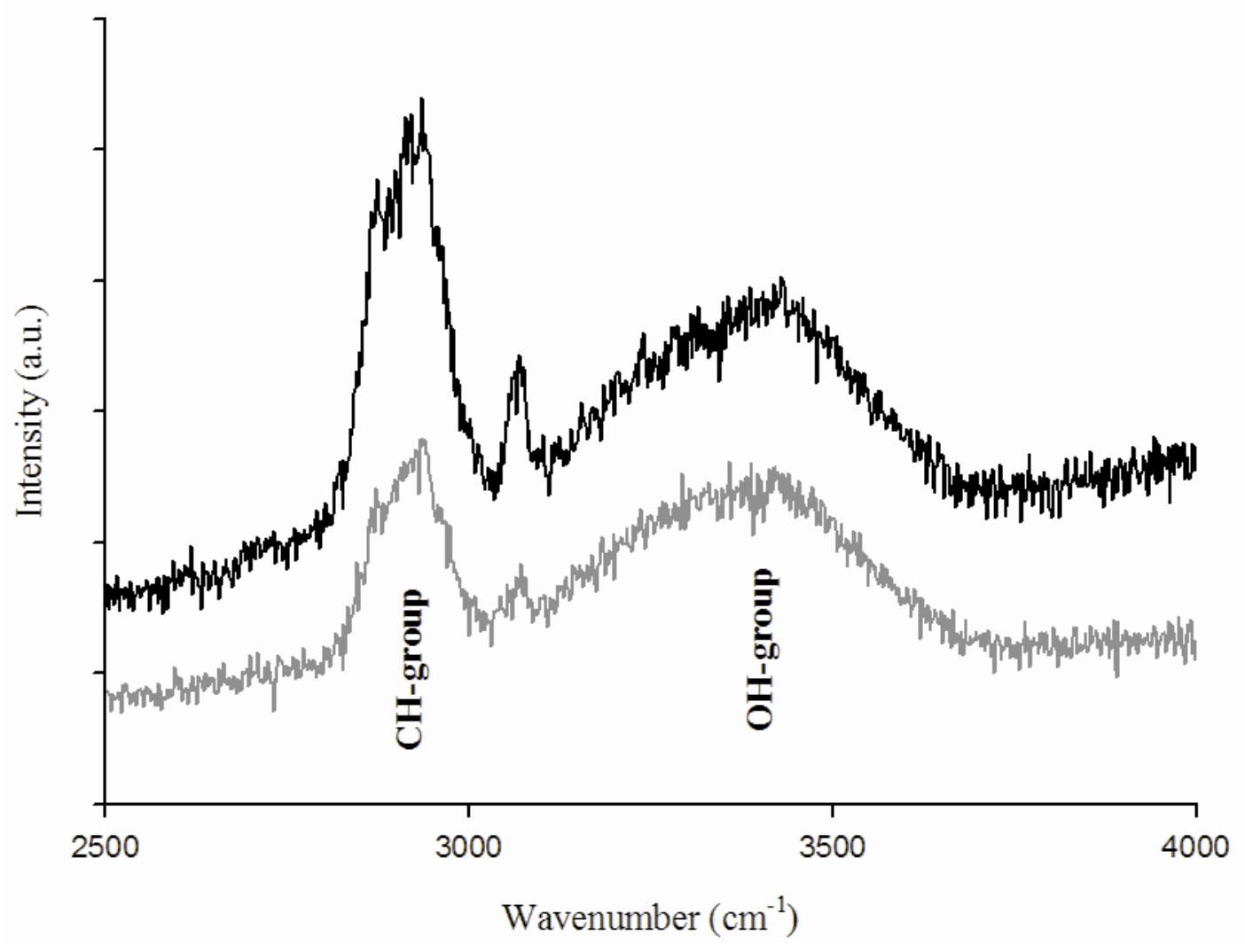


$518 \quad$ Figure 8:

$519 \quad$ (A)

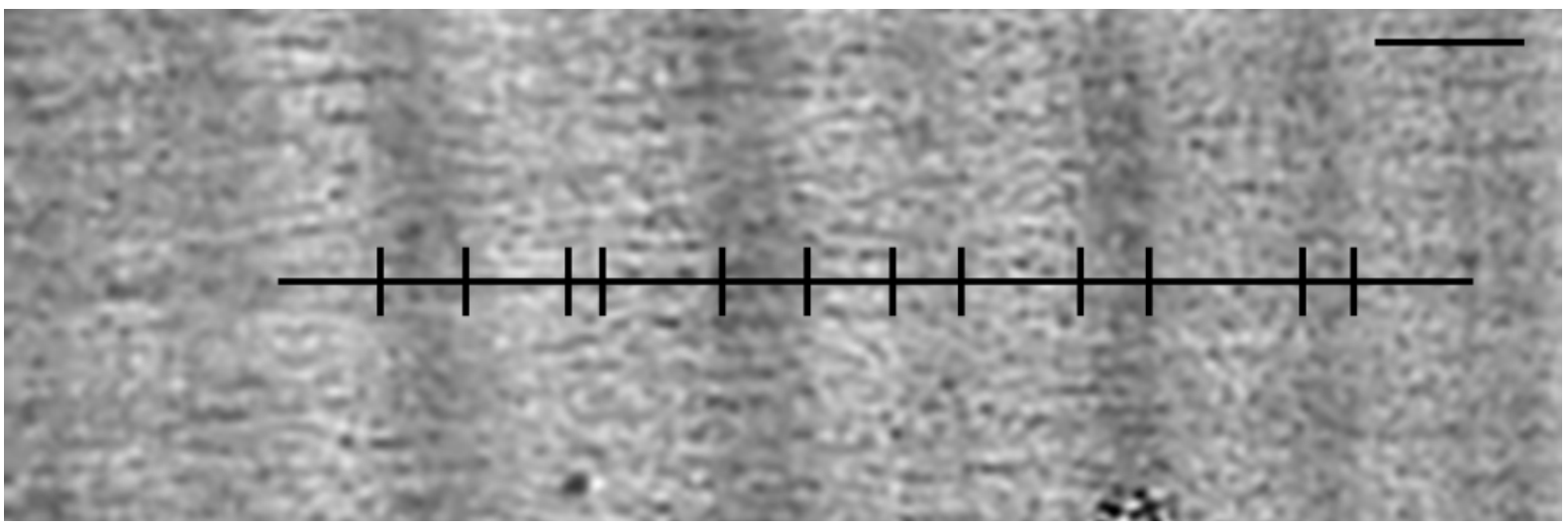

$521 \quad$ (B)

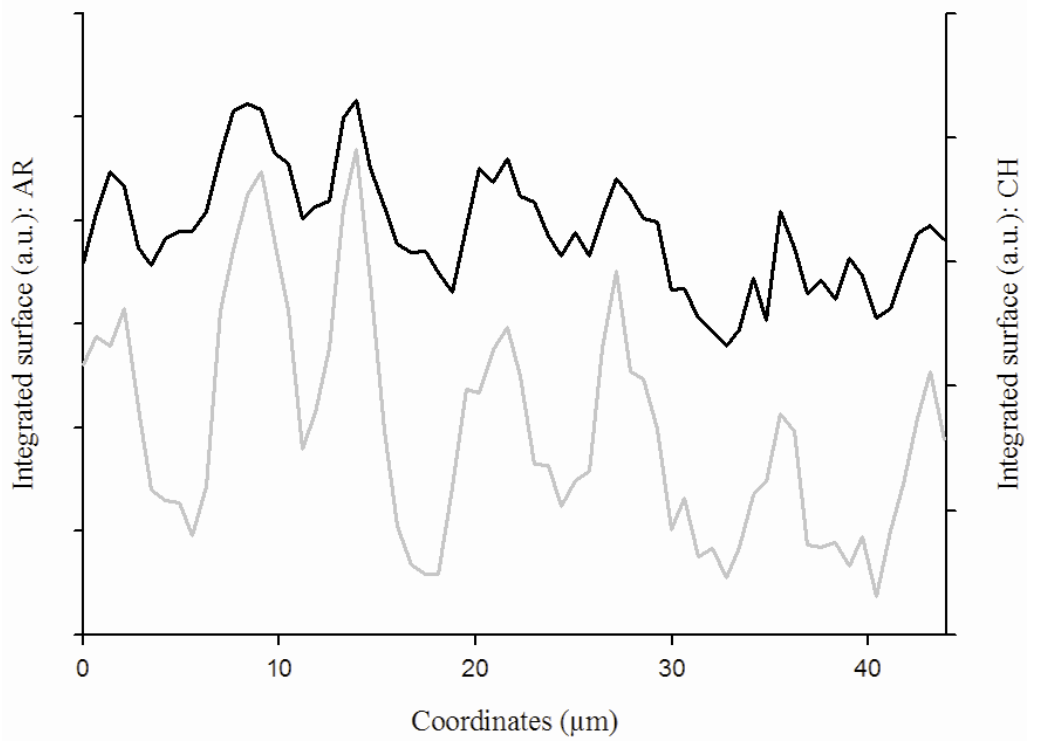

522

(C)

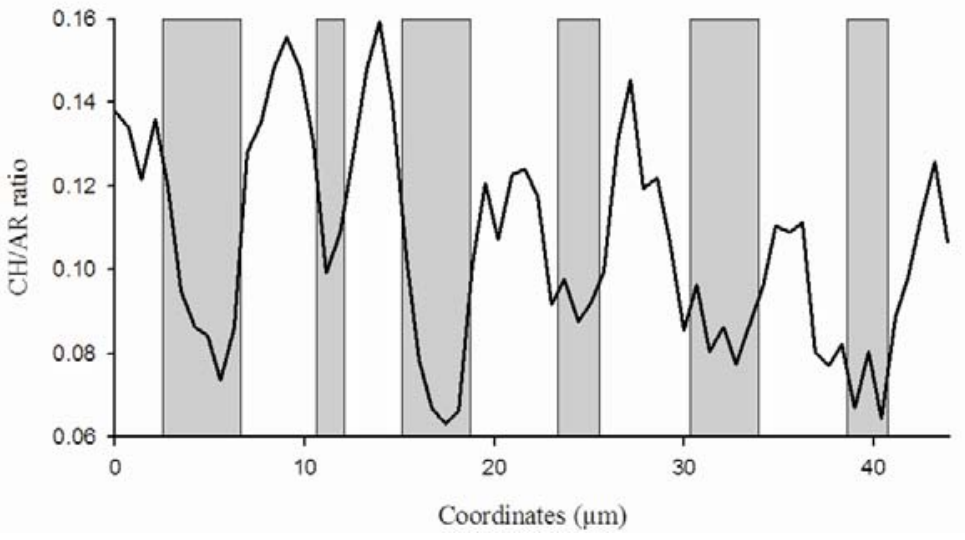




\section{$525 \quad$ Figure 9:}

526 (A)

\section{$\mid$}

527

$528 \quad$ (B)

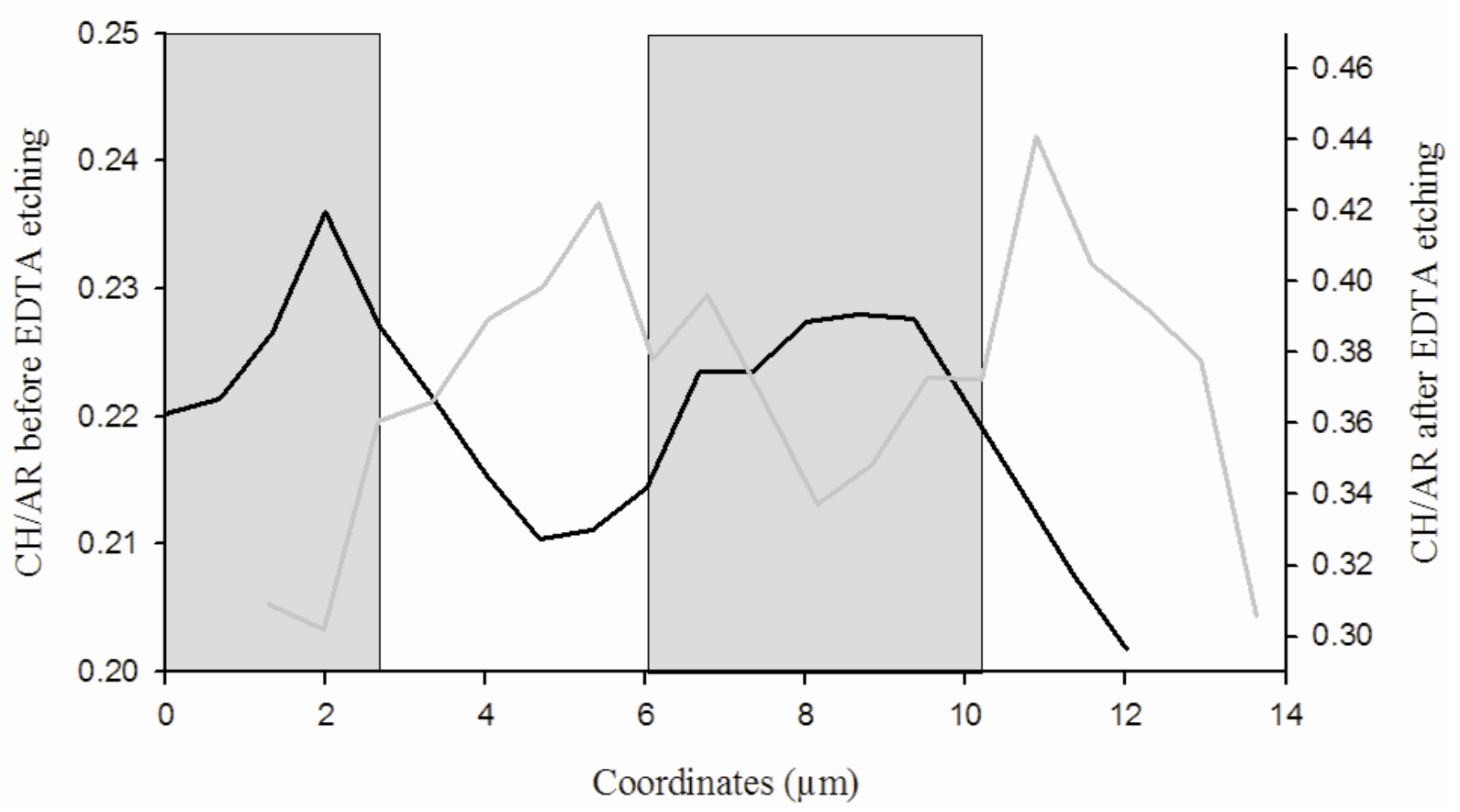


Figure 10:

$531 \quad$ (A)
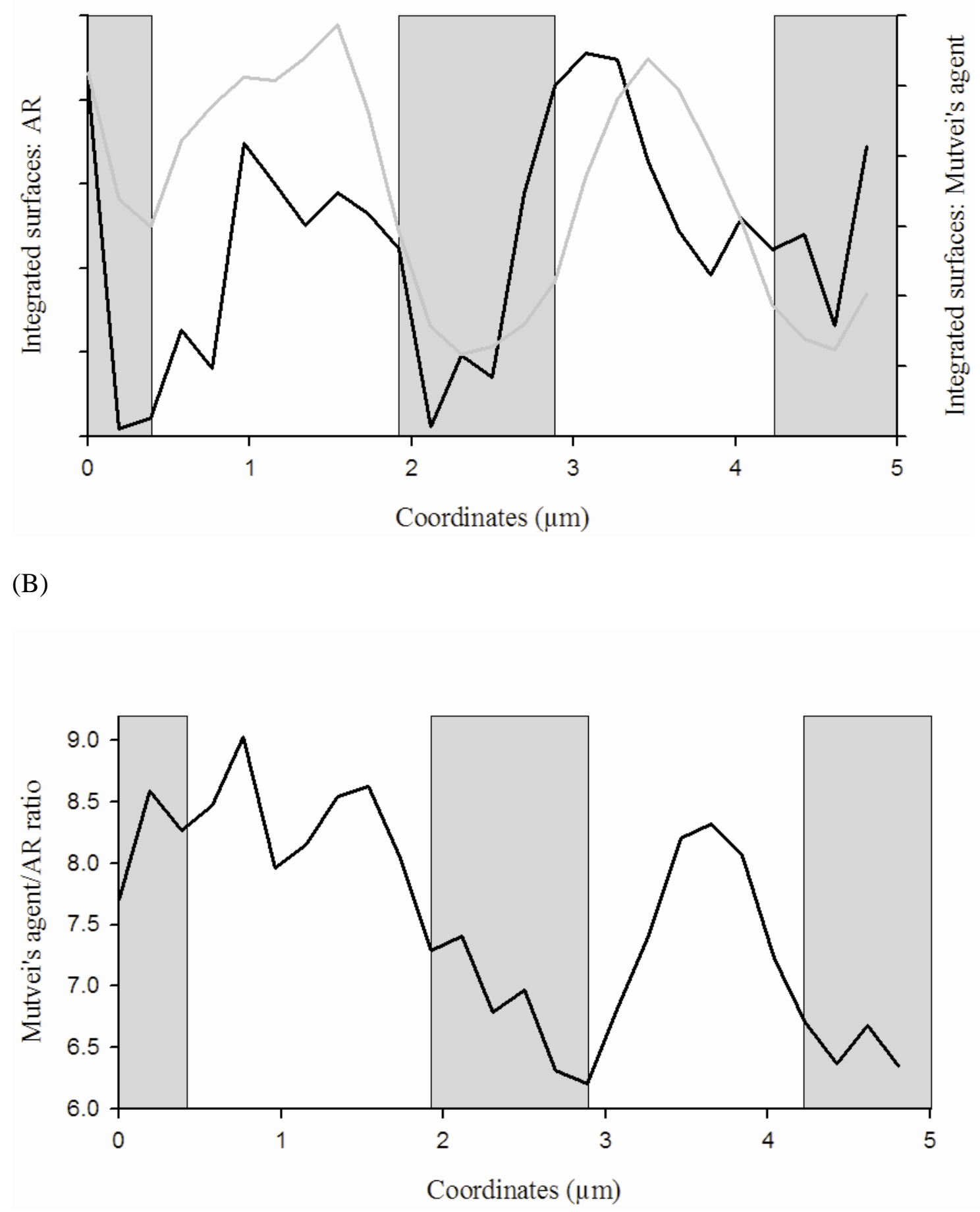